\title{
MFG-E8 Mediates Primary Phagocytosis of Viable Neurons during Neuroinflammation
}

\author{
Michael Fricker, ${ }^{1 \star}$ Jonas J. Neher, ${ }^{1 \star}$ Jing-Wei Zhao, ${ }^{2}$ Clotilde Théry, ${ }^{3}$ Aviva M. Tolkovsky,,${ }^{1,2}$ and Guy C. Brown ${ }^{1}$ \\ ${ }^{1}$ Department of Biochemistry, University of Cambridge, Cambridge CB2 1QW, United Kingdom, ${ }^{2}$ Cambridge Centre for Brain Repair, University of \\ Cambridge, Cambridge CB2 OPY, United Kingdom, and 3'Institut Curie, INSERM U932, Paris, France
}

Milk-fat globule EGF factor-8 (MFG-E8, SED1, lactadherin) is known to mediate the phagocytic removal of apoptotic cells by bridging phosphatidylserine (PS)-exposing cells and the vitronectin receptor (VR) on phagocytes. However, we show here that MFG-E8 can mediate phagocytosis of viable neurons during neuroinflammation induced by lipopolysaccharide (LPS), thereby causing neuronal death. In vitro, inflammatory neuronal loss is independent of apoptotic pathways, and is inhibited by blocking the PS/MFG-E8/VR pathway (by adding PS blocking antibodies, annexin V, mutant MFG-E8 unable to bind VR, or VR antagonist). Neuronal loss is absent in Mfge8 knock-out cultures, but restored by adding recombinant MFG-E8, without affecting inflammation. In vivo, LPS-induced neuronal loss is reduced in the striatum of $M f g e 8$ knock-out mice or by coinjection of an MFG-E8 receptor (VR) inhibitor into the rat striatum. Our data show that blocking MFG-E8-dependent phagocytosis preserves live neurons, implying that phagocytosis actively contributes to neuronal death during brain inflammation.

\section{Introduction}

Phagocytes remove dead, dying, or aged cells displaying eat-me signals, such as phosphatidylserine (PS) on the target cell's surface. Exposed PS is bound by extracellular adaptor proteins, including milk-fat globule EGF factor-8 (MFG-E8, also known as lactadherin or SED1). MFG-E8 binds to exposed PS via a C2 domain and via a RGD domain to the vitronectin receptor (VR, integrin $\alpha_{\mathrm{v}} \beta_{3 / 5}$ ) on phagocytes, thereby activating phagocytosis (Hanayama et al., 2002; Elliott and Ravichandran, 2010).

Phagocytosis is normally secondary to the target cell dying by other means such as apoptosis (Savill et al., 2002; Ravichandran, 2003). However, cell death can be caused by phagocytosis of viable PS-exposed cells, and such death is here referred to as "primary phagocytosis," with the defining characteristic that inhibition of phagocytosis prevents cell death. Primary phagocytosis does not normally initiate cell death but rather executes cell death by phagocytosis, which may be induced by exposure of eat-me signals on viable target cells. This occurs, for example, during macrophage phagocytosis of "aged" erythrocytes and activated neutrophils (Föller et al., 2008; Jitkaew et al., 2009), or during development and after sublethal insults in Caenorhabditis elegans (Hoeppner et al., 2001; Reddien et al., 2001; Neukomm et al., 2011).

Received Sept. 22, 2011; revised Dec. 21, 2011; accepted Jan. 5, 2012.

Author contributions: M.F., J.J.N., and G.B. designed research; M.F., J.J.N., and J.-W.Z. performed research; M.F., J.J.N., and G.B. analyzed data; M.F., J.J.N., C.T., A.M.T., and G.B. wrote the paper.

This work was funded by the Wellcome Trust (Grant RG50995). Expression vectors encoding flag-tagged MFG-E8 and flag-tagged MFG-E8 D89E were kind gifts from Professor S. Nagata and Dr R. Hanayama, Osaka University, Japan.

${ }^{*}$ M.F. and J.J.N. contributed equally to the work.

The authors declare no competing financial interests.

This article is freely available online through the J Neurosci Open Choice option.

Correspondence should be addressed to Dr. Jonas J. Neher, at the above address. E-mail: jjn24@bioc.cam.ac.uk. DOI:10.1523/JNEUROSCI.4837-11.2012

Copyright $\odot 2012$ the authors $\quad 0270-6474 / 12 / 322657-10 \$ 15.00 / 0$
Chronic and acute neurodegenerative disorders are accompanied by inflammation, microglial activation, and neuronal loss. Inflammation is known to contribute to neuronal loss both in vitro and in vivo, but the mechanisms are unclear (Meda et al., 1995; Tan et al., 1999, 2002; Block et al., 2007; Lobsiger and Cleveland, 2007). Lipopolysaccharide (LPS) is a bacterial cell wall component activating glia via Toll-like receptor 4 (TLR4) (Hoshino et al., 1999). TLR4 also mediates the inflammatory activation of glia by endogenous ligands such as $\beta$-amyloid in Alzheimer's disease (Walter et al., 2007), HSP-60 in trauma and stroke (Lehnardt et al., 2008), and HMGB1 in stroke and multiple sclerosis (Park et al., 2004; Andersson et al., 2008). Thus, LPS has been used extensively to model inflammatory neurodegeneration (see, for example, Gao et al., 2002).

Microglia, the resident brain macrophages, can become highly phagocytic when activated (Hanisch and Kettenmann, 2007). Microglial phagocytosis is beneficial via removal of proinflammatory debris and apoptotic cells (Neumann et al., 2009; Elliott and Ravichandran, 2010), and MFG-E8 mediates microglial phagocytosis of apoptotic neurons by binding exposed PS (Fuller and Van Eldik, 2008). However, we and others have shown that viable but stressed cells can reversibly expose PS (Tyurina et al., 2007; Jitkaew et al., 2009; Neher et al., 2011; Neniskyte et al., 2011), and thus MFG-E8 could potentially mediate microglial phagocytosis of viable neurons. In this work we test whether: (1) MFG-E8 mediates the phagocytosis of neurons, which we had previously identified to occur during inflammation, (2) this phagocytosis is primary or secondary to apoptosis, (3) MFG-E8mediated primary phagocytosis occurs in vivo, and (4) blocking this process preserves neurons. We show here that the MFG-E8 pathway mediates primary phagocytosis of neurons during inflammation, and that blocking this pathway leaves viable neurons without affecting inflammation. 


\section{Materials and Methods}

All experiments were performed in accordance with the UK Animals (Scientific Procedures) Act (1986) and approved by the Cambridge University local ethical committee.

Cell culture and treatments. Mixed neuronal/glial cultures were prepared from the cerebella of postnatal day 5-7 rats or mice as previously described (Kinsner et al., 2005) and were allowed to mature in vitro for at least $6 \mathrm{~d}$ before treatment, when they contained $85 \pm 5 \%$ neurons, $7 \pm$ $3 \%$ astrocytes, and $5 \pm 3 \%$ microglia. Microglia were selectively eliminated from cultures by addition of L-leucine methyl ester (LME; Sigma) as previously described (Neher et al., 2011). Lipopolysaccharide (LPS, Sigma) was used at $100 \mathrm{ng} / \mathrm{ml}$. Mfge 8 knock-out mice were genotyped as previously described (Silvestre et al., 2005). Neuronal and microglial cell survival was quantified $3 \mathrm{~d}$ after stimulation as previously described (Neher et al., 2011). Wild-type and D89E MFG-E8 were purified as previously described (Hanayama et al., 2002) and were used at $0.4 \mu \mathrm{g} / \mathrm{ml}$ for reconstitution and $2.0 \mu \mathrm{g} / \mathrm{ml}$ for inhibition. Cyclo(RGDfV) (cRGD; Bachem) was used at $50 \mu \mathrm{M}$ and boc-aspartyl(OMe)-fluoromethylketone at $100 \mu \mathrm{M}$. Anti-PS ( $5 \mu \mathrm{g} / \mathrm{ml}$; Abcam) blocking antibody was Fc-blocked with an $\mathrm{F}\left(\mathrm{ab}^{\prime}\right) 2$ fragment antibody (Jackson ImmunoResearch). Phagocytic capacity of microglia was assessed as previously described (Neher et al., 2011). Inflammatory mediators were assessed in culture media at $3 \mathrm{~d}$ after stimulation using Quantikine ELISA Kits (R\&D Systems) or the Griess reaction for nitrite detection (Kinsner et al., 2005).

$\beta$-Galactosidase activity and immunocytochemistry. Mfge 8 knock-out mice express a $\beta$-galactosidase-containing fusion protein under the control of the endogenous $M f g e 8$ promoter (Silvestre et al., 2005). To visualize $\beta$-galactosidase activity, cells were washed, then fixed in PBS, $2 \%$ formaldehyde, $0.2 \%$ glutaraldehyde for $5 \mathrm{~min}$ at room temperature (RT). Cells were washed and stained in $5 \mathrm{~mm}$ potassium ferricyanide, $5 \mathrm{~mm}$ potassium ferrocyanide, $2 \mathrm{~mm} \mathrm{MgCl}_{2}, 1 \mathrm{mg} / \mathrm{ml} \mathrm{X}$-gal, $6-8 \mathrm{~h}, 37^{\circ} \mathrm{C}$. Cells were washed, briefly permeabilized with $0.3 \%$ Triton X-100 and blocked with PBS, 5\% goat or donkey serum. Primary antibodies were incubated with cells for $2 \mathrm{~h}$ at RT, or overnight at $4^{\circ} \mathrm{C}$, washed, and incubated with Alexa Fluor 488- or Cy3-conjugated secondary antibody for $1 \mathrm{~h}$ at RT. Cells grown on coverslips were mounted using FluorSave (Calbiochem). For confocal detection of microglial phagocytosis of neurons, mixed neuronal cultures were plated on poly-L-lysine-coated coverslips, cultured for $7 \mathrm{~d}$ and then treated as indicated for $\sim 60 \mathrm{~h}$ before labeling of microglia with Alexa Fluor 488-labeled isolectin-B4 (IB4; $1 \mu \mathrm{g} / \mathrm{ml}$, Invitrogen) followed by fixation for $10 \mathrm{~min}$ at room temperature in $4 \%$ paraformaldehyde (PFA; Sigma). Cells were washed 3 times in PBS before permeabilization in PBS $0.3 \%$ Triton X-100 for 10 min. Blocking was performed in 5\% goat serum in PBS for $1 \mathrm{~h}$ at RT, followed by incubation with anti-NeuN primary antibody (1:100, Millipore) in PBS, $2.5 \%$ goat serum for $1 \mathrm{~h}$ at RT. After 3 PBS washes, coverslips were incubated with goat anti-mouse-Cy3 (1:250, Jackson ImmunoResearch) in PBS, 2.5\% goat serum, for $1 \mathrm{~h}$ at RT before 3 washes in PBS and mounting on slides for confocal imaging. For MFG-E8 opsonization and immunodetection Mfge8 knock-out microglia were purified and seeded on poly-L-lysinecoated coverslips in $500 \mu \mathrm{l}$ of $M$ fge 8 knock-out conditioned medium. After a $24 \mathrm{~h}$ incubation period half of the $M f g e 8$ knock-out conditioned medium was replaced with conditioned medium from wild-type mixed astroglial cultures and left for $12 \mathrm{~h}$ before further addition of $250 \mu \mathrm{l}$ of conditioned medium from wild-type astroglial cultures and another $12 \mathrm{~h}$ incubatory period. Microglia were then washed with HBSS and incubated with goat anti-MFG-E8 antibody $(4 \mu \mathrm{g} / \mathrm{ml}$, Santa Cruz Biotechnology) in HBSS supplemented with $5 \%$ donkey serum for $1 \mathrm{~h}$ at $37^{\circ} \mathrm{C}$, $5 \% \mathrm{CO}_{2}$. Cultures were washed in PBS and fixed in 4\% PFA before addition of anti-goat-Cy3 (1:250, Jackson ImmunoResearch) for $1 \mathrm{~h}$ at RT. Microglia were labeled with IB4 before mounting. Triton X-100 was excluded in detection of cell surface MFG-E8 as we found that extracellular MFG-E8 staining is detergent sensitive.

Surgical procedure. Ten-week-old male Wistar rats and male C57BL/6 or Mfge 8 knock-out mice were used for bilateral striatal stereotactic injections. Animals were maintained under anesthesia with isoflurane throughout, mounted in a stereotactic frame (Stoelting) and injected at the following coordinates relative to bregma: For rats, anterior-posterior
$(\mathrm{AP})+1.0$, mediolateral $(\mathrm{ML}) \pm 2.6$, and dorsoventral $(\mathrm{DV})-5.0 \mathrm{~mm}$. Coordinates for mice were AP $+0.7, \mathrm{ML} \pm 1.7, \mathrm{DV}-3.0 \mathrm{~mm}$. Rats received bilateral injections $(2 \mu \mathrm{l})$ of either (1) HBSS and LPS $(5 \mu \mathrm{g})$, or (2) cRGD ( $1 \mathrm{~mm})$ and cRGD +LPS. Mice received bilateral injections $(1 \mu \mathrm{l})$ of HBSS and LPS $(1 \mu \mathrm{g})$. Infusion was at $24 \mu \mathrm{l} / \mathrm{h}$ using a $31 \mathrm{G}$ stainless steel needle, which was left in place for $2 \mathrm{~min}$ after injection to prevent back-flow. At specified time points, animals were deeply anesthetized with pentobarbitol and transcardially perfused with cold PBS $(0.01 \mathrm{M}, \mathrm{pH}$ 7.4), followed by $4 \%$ PFA [0.1 M phosphate buffer (PB), $\mathrm{pH}$ 7.4]. Brains were kept in PFA for $24 \mathrm{~h}$, then $30 \%$ sucrose solution $(0.1 \mathrm{M} \mathrm{PB}, \mathrm{pH} 7.4)$ for at least 3-4 d, and cut into $40-\mu \mathrm{m}$ (rats)- or 20- $\mu \mathrm{m}$ (mice)-thick coronal sections on a sliding microtome (Leica).

Immunohistochemistry. Sections were incubated for $2 \mathrm{~h}$ at RT in PBS plus 5\% normal serum of the secondary antibody species and $0.3 \%$ Triton X-100 (all Sigma). For MFG-E8 staining the detergent was omitted. Sections were incubated with primary antibodies overnight, $4^{\circ} \mathrm{C}$ (for control staining the antibody was omitted), washed, and incubated with the secondary antibody for $2 \mathrm{~h}, 4^{\circ} \mathrm{C}$. Sections were washed, mounted and coverslipped using FluorSave reagent. Antibodies used were anti-NeuN (Millipore Bioscience Research Reagents, 1:500), anti- $\beta$-tubulin III (Sigma, 1:500), anti-MFG-E8 (Santa Cruz Biotechnology, 1:50), antiThy1.1 (supernatant of hybridoma cells OX7), anti-cleaved caspase-3 (Cell Signaling Technology, 1:200), anti $\beta$-galactosidase (Millipore Bioscience Research Reagents, 1:250), anti-Neuron-specific enolase (Bioworld, 1:50), and IB4 (1 $\mu \mathrm{g} / \mathrm{ml}$, Invitrogen). Secondary antibodies were from Jackson ImmunoResearch (1:200). For TUNEL/NeuN/IB4 labeling, sections were stained using a TUNEL kit (Roche), then with anti-NeuN antibody and biotinylated isolectin-B4 (Sigma, 1:200; $48 \mathrm{~h}, 4^{\circ} \mathrm{C}$ ). Sections were washed, incubated with donkey anti-mouseCy3 antibody (Jackson ImmunoResearch, 1:100), washed, and treated with Streptavidin-Alexa Fluor 647 (Invitrogen, 1:500), $2 \mathrm{~h}$ each, at RT. Fluoro-Jade C staining was performed after immunohistochemistry for NeuN. Sections were mounted on SuperfrostPlus slides (VWR International), dried for $20 \mathrm{~min}$ on a heating block $\left(45^{\circ} \mathrm{C}\right)$, briefly rehydrated in $\mathrm{ddH}_{2} \mathrm{O}$, blocked with freshly prepared $0.06 \%$ $\mathrm{KMnO}_{4}$ for $10 \mathrm{~min}$ at $\mathrm{RT}$, washed with $\mathrm{ddH}_{2} \mathrm{O}$, and incubated in $0.0002 \%$ Fluoro-Jade C (Millipore) solution in $0.1 \%$ acetic acid for 15 min at RT, rinsed with $\mathrm{ddH}_{2} \mathrm{O}$, dried, and coverslipped. Sections were analyzed on an Olympus Fluoview 300 confocal microscope.

Quantification of neuronal densities in vivo. Five coronal sections were analyzed per animal at coordinates $\mathrm{AP}+0.6,+0.8,+1.0,+1.2$, and +1.4 $\mathrm{mm}$ for rats and $+0.5,+0.6,+0.7,+0.8$, and $+0.9 \mathrm{~mm}$ for miceidentified according to Paxinos and Watson (1982) and Paxinos and Franklin (2001), respectively. At least five microscopic fields (20×) were analyzed per section (these never contained the needle tract). Neuronal densities were determined for $3 \mathrm{~d}$ time points using $\beta$-tubulin III staining as we and others (Unal-Cevik et al., 2004) found NeuN to be an unreliable neuronal marker during acute inflammation. $\beta$-Tubulin III-positive cells were counted manually by a blinded observer. For $7 \mathrm{~d}$ time points, NeuN-positive nuclei were automatically quantified using ImageJ software after confirming complete colocalization with $\beta$-tubulin III and neuron-specific enolase staining (data not shown). Images were taken with a Leica DMI6000 microscope.

Statistical analysis. Statistical analysis was performed using SPSS software. Normality of data was verified using the Shapiro-Wilk test. In vitro data were analyzed using one-way ANOVA and post hoc Bonferroni test. In vivo data were analyzed based on raw data using ANOVA and post hoc Sidak test (but in some cases are presented as normalized data for ease of comparison). Ipsilateral/contralateral counts were specified as resulting from the same animal (ANCOVA for condition with animal ID as covariate). Results were considered significant if $p<0.05$.

\section{Results}

LPS-induced loss of neurons requires microglia, occurs independently of apoptosis and requires PS recognition We first tested whether LPS could induce neuronal loss mediated by microglial phagocytosis of neurons in mixed neuronal/glial cultures prepared from mouse cerebella, as we have previously 
A
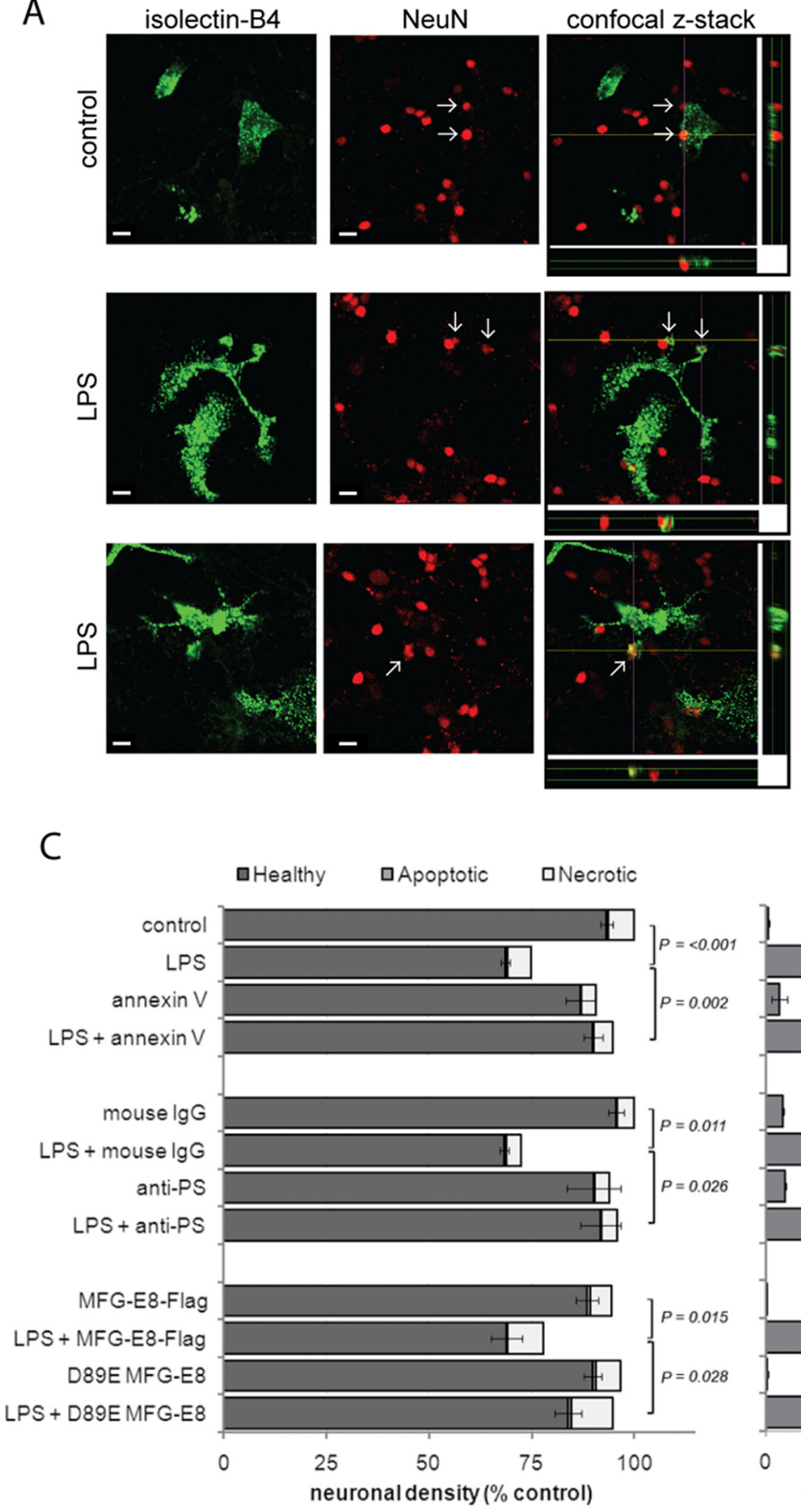

B
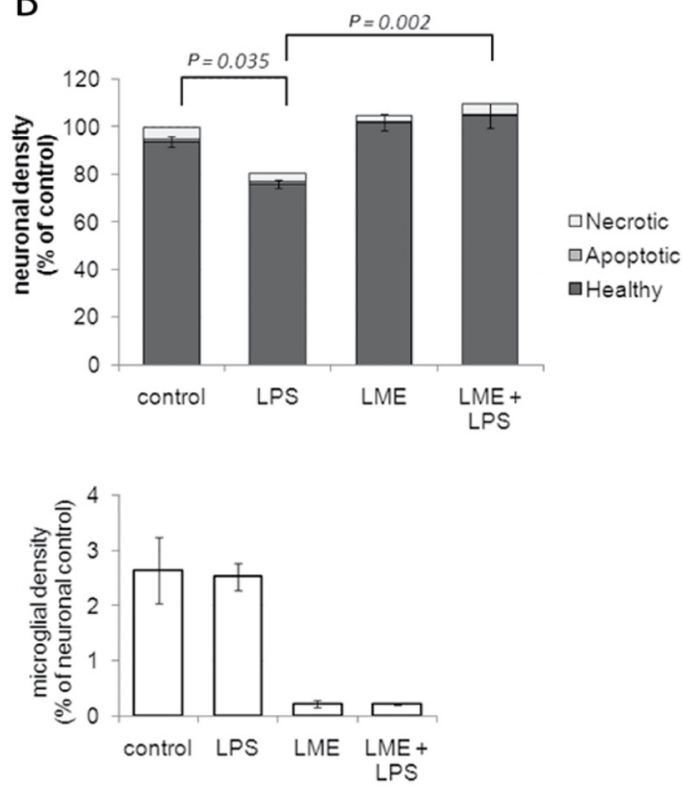

Figure 1. LPS induces neuronal death that is dependent on microglia and phagocytic PS recognition. $\boldsymbol{A}$, LPS-activated microglia phagocytose neurons. Microglia are labeled in green using Alexa Fluor 488-labeled IB4, NeuN-labeled neuronal nuclei are displayed in red. Confocal $z$-stacks indicated by the yellow $(x)$ and purple $(y)$ lines are displayed below and to the right of the merged image, respectively. Scale bar, $10 \mu \mathrm{m}$. B, Elimination of microglia from mixed neuronal cultures (using LME) prevents LPS-induced neuronal loss over $3 \mathrm{~d}$ ( $n=3$ ). C, Blocking PS recognition (AnnexinV, anti-PS antibody, D89E MFG-E8) prevents LPS-induced neuronal death (left) without affecting microglial activation (center) ( $n=3$ ). Data are means \pm SEM. Right, Purification of Flag-tagged MFG-E8 WT and D89E proteins, separated by SDS-PAGE for Coomassie and Western blot analysis. Both WT and D89E MFG-E8 were detectable at 58 kDa, the expected molecular mass of glycosylated secreted MFG-E8. Levels of contaminating proteins were minimal.

reported for rat cultures (Neher et al., 2011). Indeed, mixed cultures prepared from mouse cerebella showed both phagocytosis of neurons by microglia (Fig. 1A) and a significant decrease in neuronal density following stimulation with LPS for $3 \mathrm{~d}$ without any increase in apoptosis or necrosis (Fig. $1 B$, top). Specific depletion of microglia from the mixed cultures by LME treatment was sufficient to prevent LPS-induced loss, demonstrating that LPS was not directly toxic to neurons and that microglia were required for neuronal loss (Fig. 1B). We have previously shown in rat cultures that inflammatory activation of glia results in PS exposure on neurons and their subsequent phagocytosis (Neher et al., 2011). Therefore, we tested next whether cell surface exposure of the eat-me signal PS was required for neuronal loss. Inhibiting PS recognition through addition of either annexin V (a PS-binding protein), or an anti-PS antibody completely prevented LPS-induced neuronal loss, indicating that blocking of 
exposed PS was sufficient to block neuronal loss. Similarly, the addition of mutant MFG-E8, which binds (and masks) PS but lacks VR binding (due to a D89E mutation in the RGD domain; Asano et al., 2004) was sufficient to prevent neuronal loss, whereas wild-type MFG-E8 had no effect (Fig. 1C). Importantly, none of the PS blocking agents prevented inflammatory activation of microglia, as assessed by TNF- $\alpha$ production (Fig. 1C). Thus LPS-induced neuronal loss was dependent on the presence of microglia and was inhibited by agents blocking PS recognition. More importantly, inhibition of PS recognition by all three agents prevented not just neuronal loss but also neuronal death leaving live neurons, indicating that PS-dependent phagocytosis of neurons was the cause of neuronal death.

PS exposure is frequently associated with the early stages of apoptosis. To rule out apoptosis as a mechanism of death and PS exposure in our model we prepared cultures from Bax knock-out mice. Postmitotic neurons are wholly reliant on the expression of Bax for induction of apoptosis via the mitochondrial pathway, as they do not express full-length Bak (Deckwerth et al., 1996; Sun et al., 2001). Genetic ablation of Bax had no effect on LPS-induced neuronal loss compared with cultures from Bax-heterozygote mice or Bax wild-type mice (Fig. 2A). Thus the mitochondrial pathway of apoptosis is not involved in LPS-induced neuronal loss. However, apoptosis may also be triggered by death receptors, leading to cell death mediated by caspases. We previously demonstrated that caspase inhibitors prevented inflammationinduced neuronal loss (Kinsner et al., 2005). However it is now known that caspases also play a role in inflammatory processes (see, for example, Lamkanfi, 2011). To avoid an inhibitory effect on inflammatory activation, we added caspase inhibitors $24 \mathrm{~h}$ after LPS stimulation, a time point we previously demonstrated to precede phagocytic loss of neurons in vitro (Neher et al., 2011). Addition of the pan caspase inhibitor boc-aspartyl(OMe)fluoromethylketone (BAF) $24 \mathrm{~h}$ after LPS stimulation failed to protect neurons against LPS-induced loss (Fig. $2 \mathrm{~B}$ ) and did not affect inflammatory activation (data not shown). To demonstrate the efficacy of caspase inhibition by BAF, we induced apoptosis in the neurons using etoposide, and as expected BAF inhibited etoposide-induced death (Fig. 2C), verifying its efficacy as an inhibitor of apoptosis. Thus, LPS-induced inflammation resulted in neuronal death independent of apoptotic pathways, but rather mediated through microglial phagocytosis via a PS-dependent pathway.

\section{MFG-E8 is required for LPS-induced neuronal loss in vitro}

The soluble PS-binding protein MFG-E8 and its receptor, VR, are required for recognition and phagocytosis of PS-exposing targets in numerous cellular settings (see, for example, Hanayama et al., 2002; Fuller and Van Eldik, 2008). To test whether MFG-E8 mediates LPS-induced neuronal loss we prepared mixed neuronal/ glial cultures from Mfges knock-out mice. In contrast to wildtype cultures, $M f g e 8$ knock-out cultures showed no significant loss of viable neurons following LPS treatment (Fig. 3A). Importantly, Mfges knock-out microglia showed identical inflammatory activation following LPS treatment compared with their wild-type counterparts as assessed by the release of the proinflammatory cytokines TNF- $\alpha$ and IL-6 (Fig. 3B). Furthermore, both wild-type and Mfges knock-out microglia ingested similar numbers of fluorescently labeled microspheres in a phagocytosis assay, with both displaying an approximate twofold increase in the number of microspheres ingested following LPS stimulation (Fig. 3C). Thus, the lack of LPS-stimulated primary phagocytosis in Mfges knock-out cultures was not due to a general inactivation
A
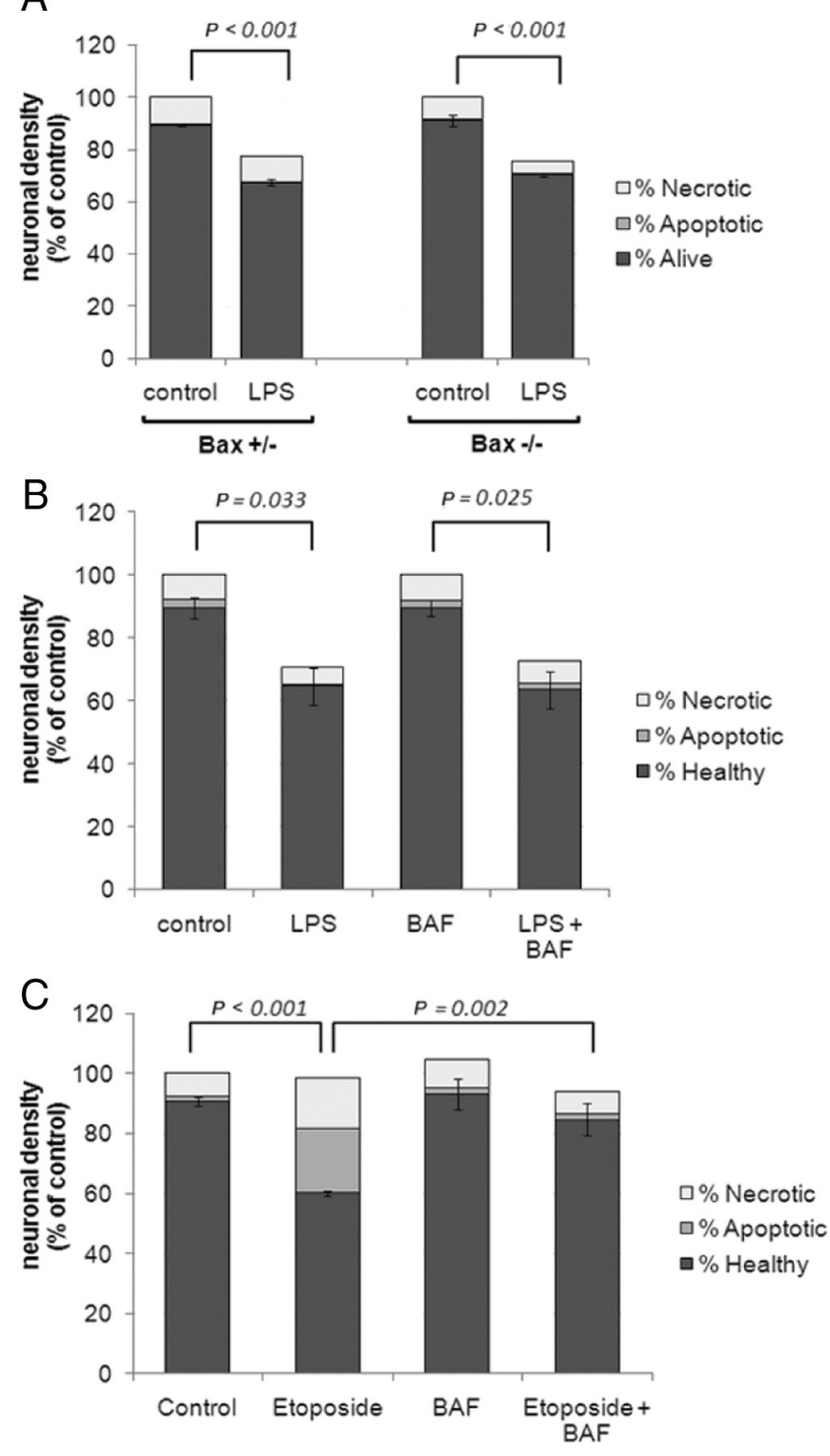

Figure 2. LPS-induced neuronal loss is independent of apoptotic pathways. $A$, Bax knockout does not prevent LPS-induced loss of neurons $(n=3)$. B, C, Pan-caspase inhibitor BAF rescues neurons from etoposide-induced death, but does not protect neurons from $L P S$-induced death $(B, n=3 ; \boldsymbol{C}, n=5)$. Data are means \pm SEM.

of phagocytosis or lack of inflammatory activation in Mfges knock-out microglia.

To test whether the lack of primary phagocytosis observed in Mfge8 knock-out cultures was indeed due to the deficiency of exogenous MFG-E8 rather than some secondary effect, we added exogenous MFG-E8 back to the cultures (after expression and purification of a flag-tagged version of MFG-E8; Fig. 1C, right). While addition of MFG-E8 to untreated knock-out cultures had no effect on neuronal number, addition of wild-type MFG-E8 to LPS-treated knock-out cultures reconstituted loss of viable neurons (Fig. 3D). Furthermore, addition of the mutant D89E MFGE8, which cannot bind to VR (Asano et al., 2004), was unable to restore primary phagocytosis in $M f g e 8$ knock-out cultures. In addition, cRGD, a specific inhibitor of the VR that mimics the RGD domain of MFG-E8 (Haubner et al., 1996), significantly reduced the loss of neurons induced by LPS in cultures prepared from wild-type mice, without preventing inflammatory activation of microglia (Fig. 3E). Thus, MFG-E8 expression and its 
A

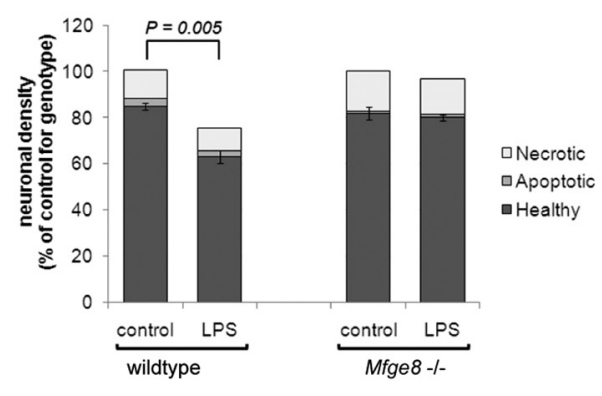

$\mathrm{D}$

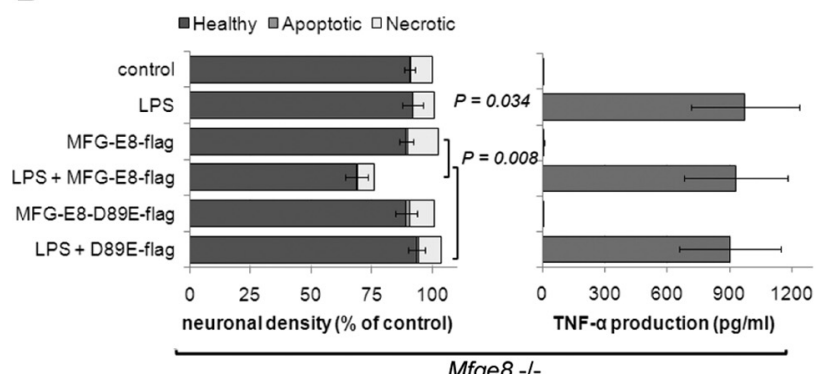

B

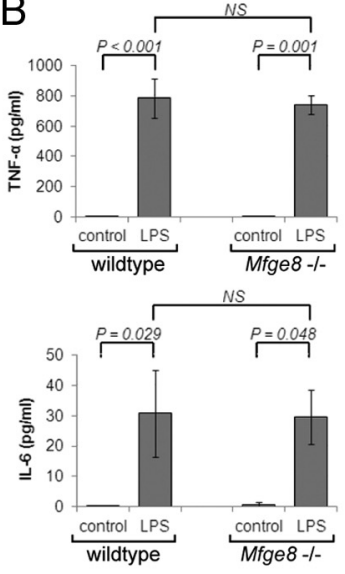

C

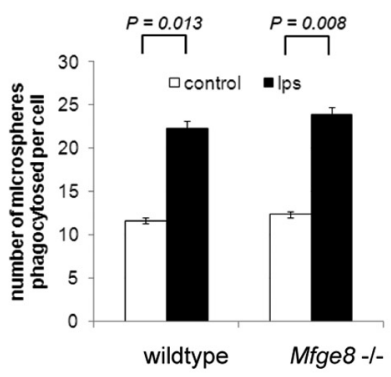

$\mathrm{E}$
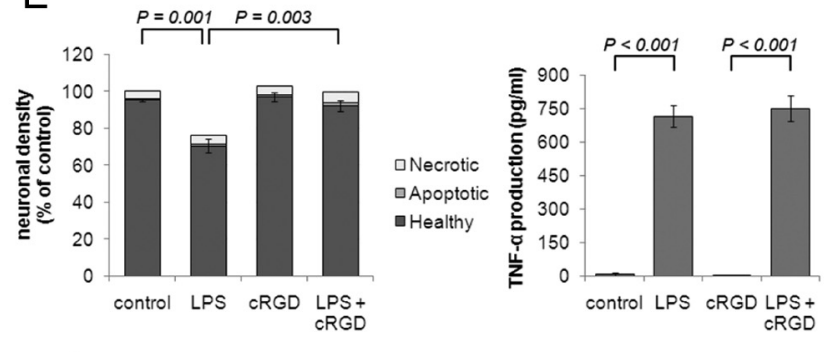

wildtype

Figure 3. MFG-E8/VR are required for LPS-induced neuronal loss in vitro. A, Mixed neuronal glial cultures prepared from Mfge8 knock-out mice are completely protected from LPS-induced loss $(n=3)$. B, LPS-induced inflammatory activation as measured by TNF- $\alpha$ (top) and IL-6 (bottom) production is indistinguishable in wild-type and Mfge 8 knock-out cultures ( $n=3$ ). C, Microglia from wild-type and Mfge8 knock-out mice show an indistinguishable increase in phagocytic capacity following LPS treatment $(n=3)$. $\boldsymbol{D}$, Reconstitution of Mfge8 knock-out cultures with exogenous MFG-E8 is sufficient to restore LPS-induced neuronal loss, however a VR-binding-defective MFG-E8 protein (D89E) does not restore LPS-induced death (left, $n=3$ ). Neither WT nor D89E MFG-E8 affects the inflammatory activation by LPS as measured by TNF- $\alpha$ production (right, $n=3$ ). $E$, Vitronectin receptor antagonist, CRGD, prevents LPS-induced neuronal death without affecting inflammatory activation of cultures $(n=3)$.

recognition by VR are required for LPS-induced primary phagocytosis to proceed in vitro.

To test whether microglia were a source of MFG-E8, we reconstituted microglia-deficient (LME-treated) Mfges knock-out cultures with either wild-type or Mfges knock-out microglia. Upon stimulation with LPS we observed a significant loss of viable neurons in $M f g e 8$ knock-out cultures reconstituted with wildtype microglia, while no loss was observed in cultures where Mfges knock-out microglia had been added back (Fig. 4A). This indicates that wild-type microglia are necessary and sufficient for LPS-induced neuronal loss.

Analyzing mixed cultures prepared from knock-out mice, which express a $\beta$-galactosidase gene under the control of the endogenous Mfge8 promoter (Silvestre et al., 2005), we found that astrocytes were the predominant cell type expressing MFG-E8 (Fig. 4B). However, we have previously shown that extracellular MFG-E8 protein is largely localized to the surface of microglia in mixed cultures (Fig. $4 B$; Neher et al., 2011), so it is possible that wild-type microglia are opsonized by MFG-E8 from astrocytes, transferring the protein when added to the Mfges knock-out cultures. Supporting this hypothesis we found that addition of conditioned medium from wild-type astroglial cultures was sufficient to opsonize Mfge 8 knock-out microglia with MFG-E8 protein as detected by immunocytochemistry (Fig. 4C).

\section{Lack of MFG-E8 prevents LPS-induced inflammatory neurodegeneration in vivo}

To test whether MFG-E8-dependent phagocytosis is involved in inflammatory neuronal loss in vivo, we stereotactically injected
LPS into the striatum of wild-type and Mfges knock-out mice (and saline on the contralateral side). In wild-type mice LPS injection caused strong inflammatory activation of microglia (shown by increased density of isolectin-B4 binding cells; Dehmer et al., 2000; Fig. 5A), as has previously been described (Chéret et al., 2008). Similarly, LPS injection caused strong microglial activation in Mfges knock-out mice, although the absolute number of activated microglia was somewhat lower than in wild-type animals at $3 \mathrm{~d}$. The microglial inflammatory response had mostly subsided by $7 \mathrm{~d}$ after LPS injection and microglial numbers were similar in wild-type and knock-out animals at this time (Fig. 5A).

LPS injection also resulted in significant neuronal loss in mice both at 3 and $7 \mathrm{~d}$ after striatal injection of LPS. Importantly, there was significantly less neuronal loss in Mfges knock-out animals at 3 and $7 \mathrm{~d}$ after LPS injection, indicating that MFG-E8-mediated phagocytosis significantly contributed to inflammatory neuronal death (Fig. $5 B, C$ ). To determine whether the increased neuronal density was due to accumulation of dying neurons resulting from the lack of MFG-E8, sections were stained with Fluoro-Jade C (a marker for degenerating neurons; Schmued et al., 2005). However, we found no Fluoro-Jade C-positive cells in the striatum (except directly around the needle tract) at 3 or $7 \mathrm{~d}$ after LPS injection in wild-type and Mfges knock-out animals (data not shown), indicating that the increased neuronal density in $M f g e 8$ knockout animals was not due to retention of dying cells, but due to inhibition of primary phagocytosis. 
A
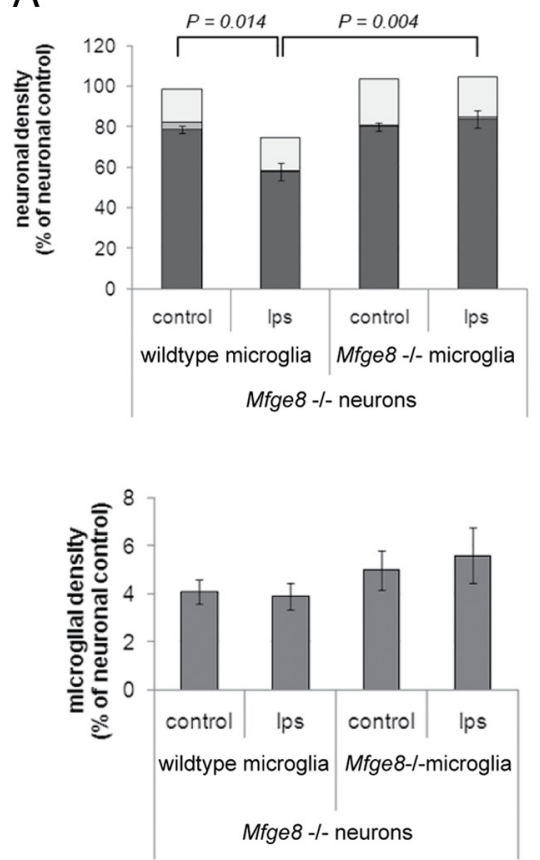

B

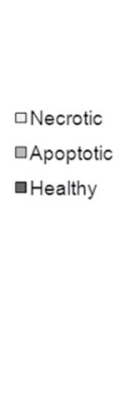

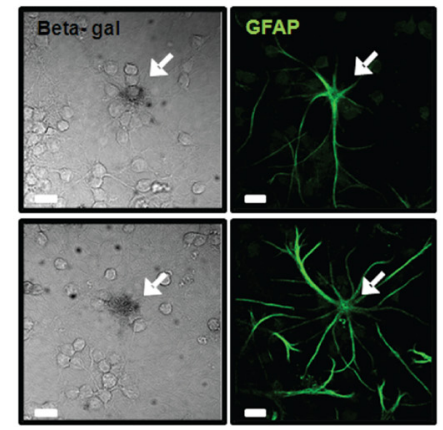
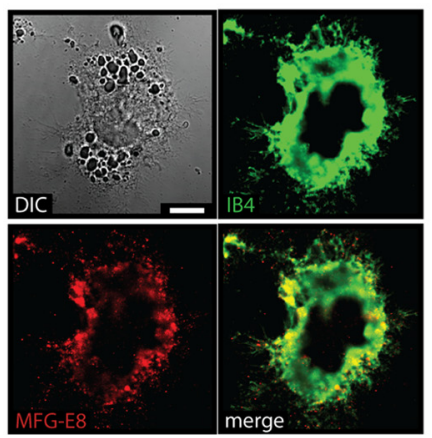

C
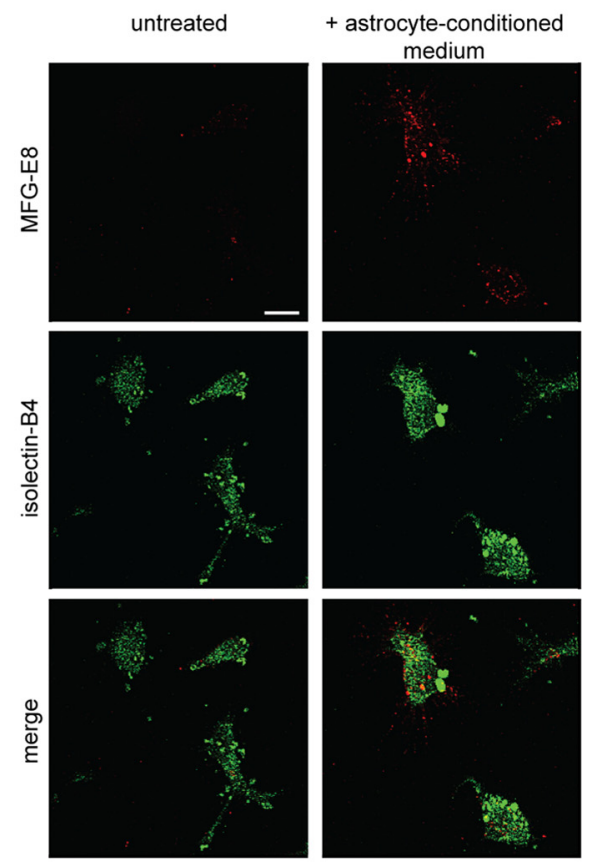

Figure 4. Microglia are a sufficient source of MFG-E8.A, Reconstitution of microglia-depleted Mfge8 knock-out cultures with wild-type microglia is sufficient to restore LPS-induced neuronal loss $(n=3)$. $\boldsymbol{B}$, MFG-E8 is largely expressed by astrocytes in vitro, although microglia are highly opsonized with MFG-E8 protein after treatment with LPS. Mfge8 knock-out cultures express $\beta$-galactosidase under control of the endogenous Mfge8 promoter. $\beta$-Galactosidase activity specific to Mfge8 knock-out cultures was largely associated with astrocytes (GFAP-positive, left). Immunocytochemistry for external MFG-E8 protein shows that wild-type microglia (IB4-positive) retain high amounts of MFG-E8 protein on their surface (right). C, Immunocytochemistry for external MFG-E8 protein shows that purified Mfge8 knock-out microglia (IB4-positive) can be opsonized with MFG-E8 protein (in red, top) present in conditioned medium from wild-type astroglial cultures. Scale bar, $10 \mu \mathrm{m}$.
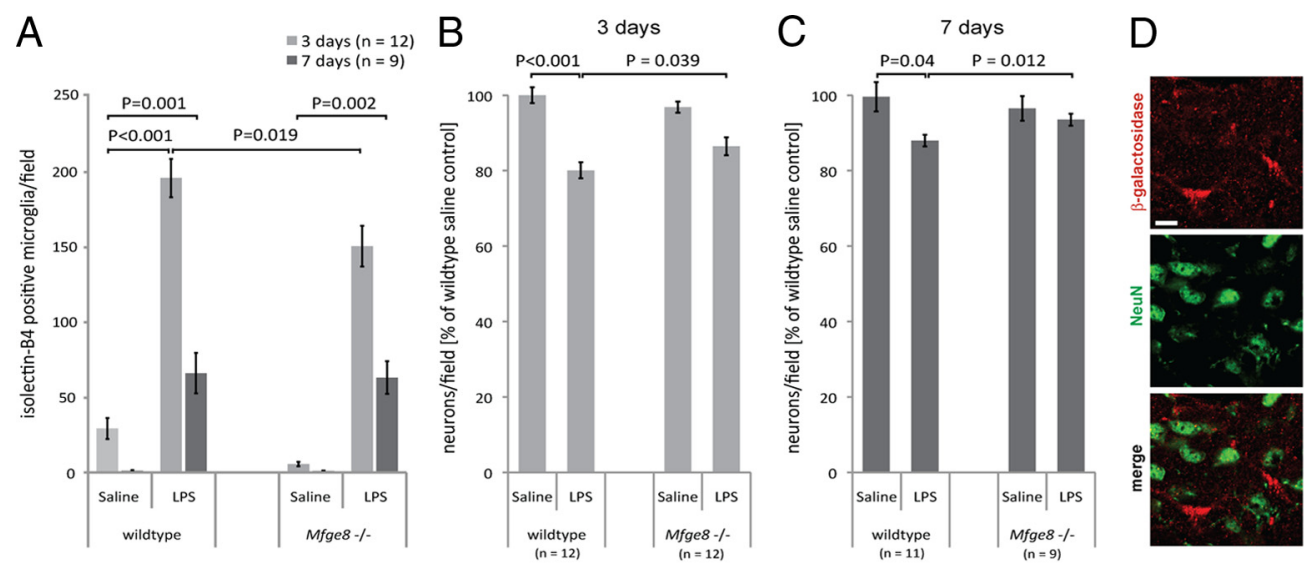

LPS injected side (3 days)

Figure 5. LPS-induced neuronal loss is reduced in the absence of MFG-E8 in vivo. A, LPS injection induces a large increase in activated microglia (stained with isolectin-B4) after $3 \mathrm{~d}$, which recedes by $7 \mathrm{~d}$. Mfge 8 knock-out animals show a slight reduction in the number of activated microglia after $3 \mathrm{~d}$. B, C, Neuronal loss after 3 and $7 \mathrm{~d}$ is reduced in Mfge 8 knock-out animals (MFG-E8 ${ }^{-1-}$ ) compared with wild-type controls (please note: the apparently smaller neuronal loss at $7 \mathrm{vs} 3 \mathrm{~d}$ may be a result of tissue contraction; unpublished observation). Data are means \pm SEM. $\boldsymbol{D}$, Expression of the $\beta$-galactosidase gene through the Mfge8 promoter in knock-out animals allows for visualization of MFG-E8 expression by $\beta$-gal immunostaining (confocal images). MFG-E8 is only expressed in LPS-injected brain, but not on the saline-injected contralateral side (data not shown). Costaining with GFAP and isolectin-B4 reveals expression in both astrocytes and microglia, respectively, but not with the neuronal marker NeuN. Scale bar, $10 \mu \mathrm{m}$ (all images).

MFG-E8 is expressed both in astrocytes and microglia in vivo As mentioned above, the $M f g e 8$ knock-out animals used here have the $\beta$-galactosidase ( $\beta$-gal) gene inserted into the $M$ fge 8 gene yielding a transmembrane protein (Silvestre et al., 2005). This allowed us to assess expression of MFG-E8 in the LPSinjected brain using $\beta$-gal immunohistochemistry. In vivo, in the saline-injected hemisphere, only very few cells around the needle tract showed $\beta$-gal expression (data not shown). In contrast, a significant number of cells expressed $\beta$-gal at $3 \mathrm{~d}$ after LPS injection. These cells were identified as astrocytes and microglia/macrophages by costaining with GFAP and isolectin-B4, respectively, with astrocytes showing much higher protein levels. In contrast, $\beta$-gal was never found to colocalize with neuronal markers (Fig. $5 D$ ). $\beta$-gal expression was weak at $7 \mathrm{~d}$ after LPS injection (data not shown), indicating that gene expression through the Mfge8 promoter was driven by acute inflammatory processes. 

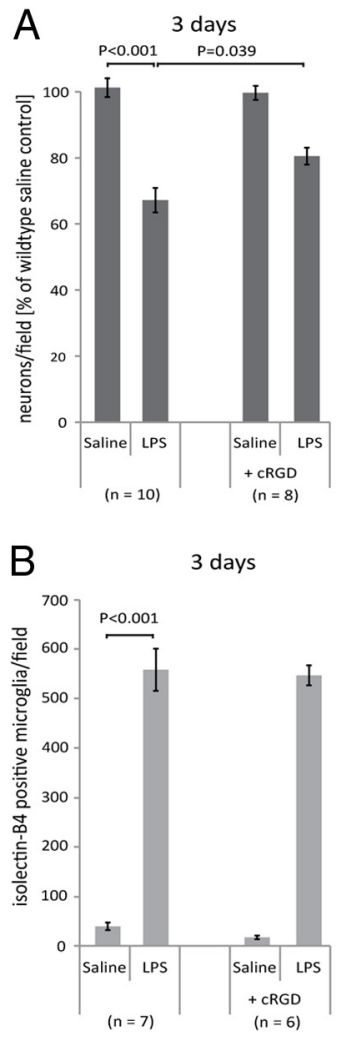
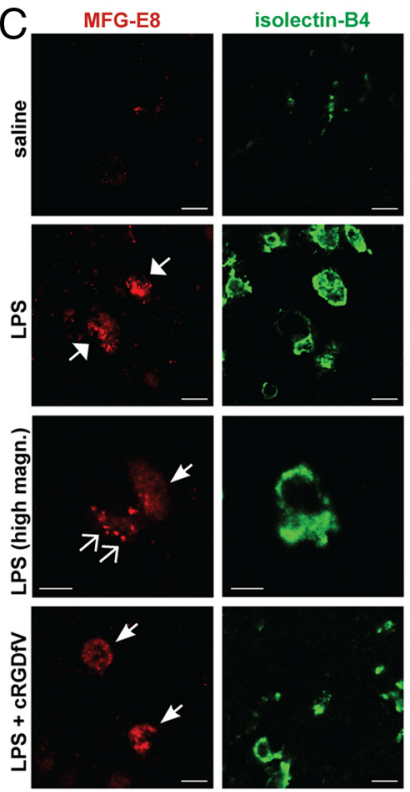

MFG-E8

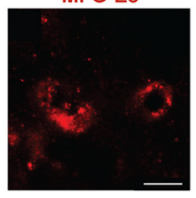

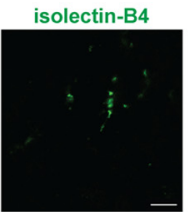
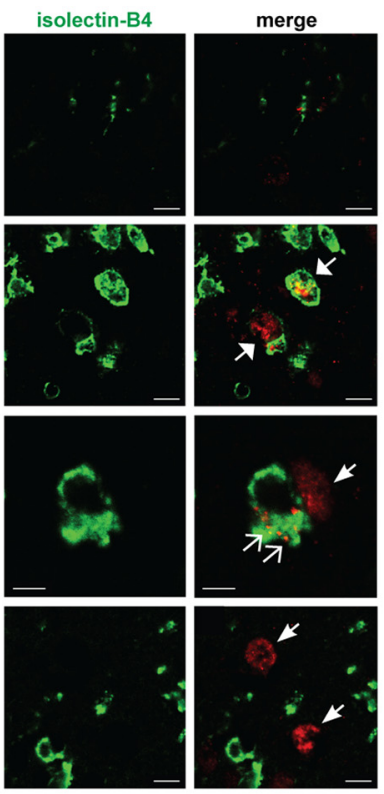

merge
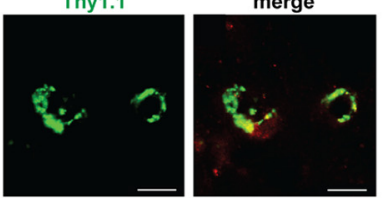
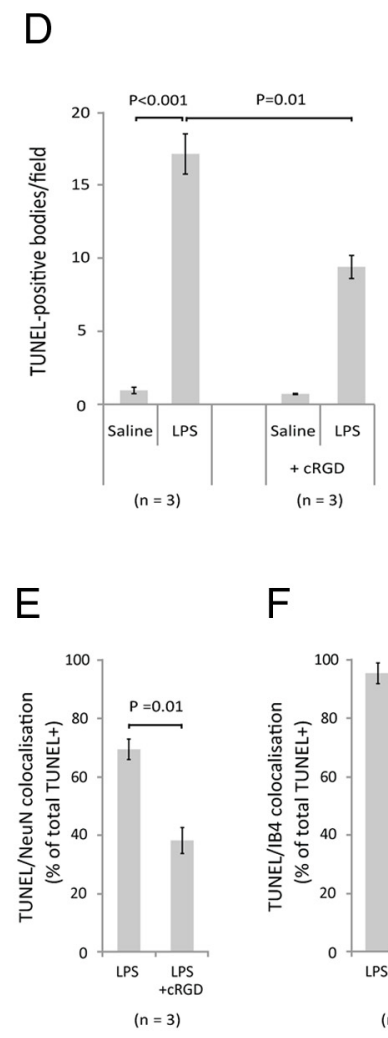

$\mathrm{F}$
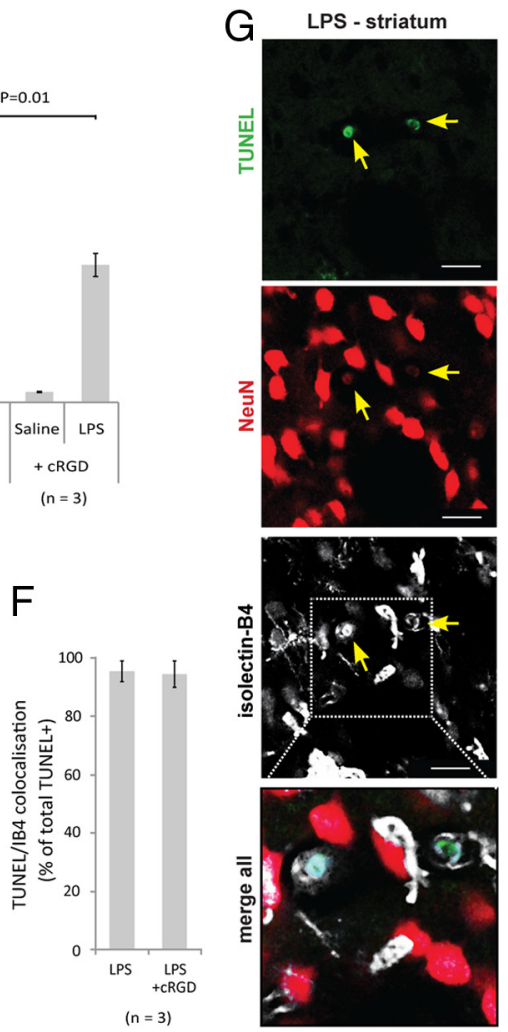

Figure 6. Inhibition of the MFG-E8 receptor reduces LPS-induced inflammatory neuronal loss. $A$, Neuronal loss at $3 \mathrm{~d}$ after LPS injection is reduced in animals coinjected with the MFG-E8 receptor (VR) antagonist, CRGD. B, LPS induces a large increase in activated microglia (stained with isolectin-B4), which is not affected by coinjection of cRGD. C, Confocal micrographs of coronal sections through the rat striatum stained for MFG-E8 (red) and microglia (isolectin-B4, green). MFG-E8-positive cells are found throughout the LPS-injected striatum, but not in the saline-injected contralateral hemisphere. MFG-E8 appears to be localized in vesicles on the microglial cell-surface (open arrows). Cells with more diffuse staining for MFG-E8 are virtually always contacted by microglia (wide filled arrows), while in animals coinjected with CRGD, MFG-E8-positive cells are isolated from microglial processes (narrow filled arrows). These cells are identified as neurons (Thy1.1). Scale bar, $5 \mu \mathrm{m}$ for LPS high magn., $10 \mu \mathrm{m}$ in all other pictures. $\mathbf{D}-\mathbf{G}$, Small TUNEL-positive inclusions are found throughout the LPS-injected striatum (confocal images in $\mathbf{G}$ ). These are virtually always located inside of IB4-positive microglia $(\boldsymbol{F})$, often colocalize with the neuronal nuclear antigen NeuN $(\boldsymbol{E})$ and are reduced by coinjection of the VR inhibitor cRGD $(\boldsymbol{D})$, indicating that neuronal death is executed by microglial phagocytosis. Scale bar, $20 \mu \mathrm{m}$. Data are means \pm SEM.

\section{Inhibition of the MFG-E8 receptor prevents LPS-induced neuronal loss in vivo}

Neuronal loss and widespread inflammation have also been described in response to intrastriatal LPS injection in rats (Nadeau and Rivest, 2002; Choi et al., 2007). As we found more robust LPS-induced neuronal loss in these animals, rats were used to assess whether pharmacological inhibition of the receptor for MFG-E8 (VR) using cRGD could also prevent LPS-induced neuronal loss in vivo. LPS injection caused a large increase in the number of activated microglia, which was not significantly affected by coinjection of cRGD (Fig. 6 B). Importantly, coinjection of the vitronectin receptor antagonist, cRGD, significantly reduced LPS-induced neuronal loss (Fig. 6A). This neuroprotective effect afforded by the inhibition of the MFG-E8 receptor against LPS-induced neurodegeneration further supports an essential role of the PS/MFG-E8/VR pathway in mediating neuronal loss in vivo.

We examined the localization of MFG-E8 in the LPS-injected rat brain. MFG-E8 was virtually absent in saline-injected brain. However, MFG-E8 was observed both on microglia and neurons after LPS injection (Fig. 6C). As reported for macrophages (Oshima et al., 2002), MFG-E8 staining was detergent-sensitive and located on microglial vesicles in the LPS-injected striatum. Importantly, MFG-E8immunoreactive neurons (identified by costaining with the neuronal cell-surface protein Thy1.1) were virtually always contacted by microglia, consistent with MFG-E8 bridging these two cell-types and acting as a signal for phagocytic uptake. Furthermore, in animals treated with LPS + cRGD, small numbers of MFG-E8-positive neurons were often found isolated from any microglial processes, consistent with the inhibitor preventing phagocytic recognition of MFG-E8-opsonized neurons in vivo. Thus, the presence of MFG-E8-opsonized neurons in LPS-injected striatum cotreated with cRGD supports the suggestion that this inhibitor prevents the phagocytic removal of these neurons and that its neuroprotective effect is therefore due to inhibition of microglial phagocytosis of otherwise viable neurons.

To confirm that the lack of neuronal loss after inhibition of MFG-E8-mediated phagocytosis in rats was not due to accumulation of dying cells, we stained sections with Fluoro-Jade C. Fluoro-Jade C-positive cells were only observed around the needle tract and never throughout the striatum (data not shown), equivalent to our observations in mice. Similarly, staining for cleaved (active) caspase-3 only showed neurons with active caspase- 3 in the direct vicinity of the injection site, but never anywhere else in the striatum for any of the conditions at $3 \mathrm{~d}$ after injection (data not shown). However, while TUNEL staining (a marker of DNA strand breaks) also revealed TUNEL-positive cells around the injection site in both saline- and LPS-injected hemispheres (data not shown), small TUNEL-positive bodies were also found distributed throughout the inflamed areas of the LPS-injected striatum (Fig. 6G), but not the contralateral hemi- 
sphere (data not shown). Triple staining for TUNEL, the neuronal nuclear marker $\mathrm{NeuN}$, and the microglial marker isolectin-B4 revealed that these bodies often colocalized with $\mathrm{NeuN}$ (Fig. 6E) and were almost always enclosed by isolectin B4-labeled microglial membranes (Fig. $6 F$ ), possibly indicating that neurons had been phagocytosed and their DNA digested inside microglia (as previously shown for phagocytosis of cells resistant to apoptotic DNA degradation; Hanayama et al., 2002). In accordance with this hypothesis, the number of TUNEL-positive bodies was highest for the LPS-injected striatum, while it was significantly reduced by coinjection of cRGD (Fig. 6D). Additionally, coinjection of cRGD strongly reduced the number of TUNEL-positive inclusions colocalizing with $\mathrm{NeuN}$ (Fig. $6 \mathrm{E}$ ), thereby indicating that degradation of neuronal DNA (stained by NeuN) only occurred when neurons were phagocytosed by microglia.

In summary, our experiments using $M f g e 8$ knock-out mice as well as pharmacological inhibition of MFG-E8 recognition in wild-type rats support a crucial role for the phagocytic bridging molecule MFG-E8 in mediating neuronal loss during LPSinduced inflammation in vivo. Furthermore, our results provide strong evidence that these inflammatory stressed neurons do not undergo cell death if they are protected from being phagocytosed by activated microglia.

\section{Discussion}

We show here that MFG-E8-mediated microglial phagocytosis can execute neuronal death during LPS-induced neuroinflammation. LPS causes loss of neurons in mixed neuronal/glial cultures without increasing neuronal apoptosis or necrosis. Removing microglia from these cultures prevented neuronal loss and readdition of exogenous wild-type microglia restored neuronal loss, indicating a requirement for microglia. LPSinduced neuronal loss was completely prevented by blocking the PS/MFG-E8/VR pathway of phagocytosis with either: annexin V or anti-PS antibodies to block exposed PS, mutant MFG-E8 unable to bind VR, or cRGDfV to block VR. In each case, blocking this pathway of phagocytosis prevented neuronal loss without increasing neuronal apoptosis or necrosis, suggesting that the phagocytosis was primary rather than secondary to apoptosis or necrosis, i.e., phagocytosis was the cause of neuronal death. This conclusion is further supported by the finding that inhibition of apoptosis with the pan-caspase inhibitor BAF did not prevent neuronal loss. LPS-induced neuronal loss was also unaffected in cultures from Bax-knock-out mice, which because full-length Bak is lacking in the brain (Deckwerth et al., 1996; Sun et al., 2001) indicates that the intrinsic, mitochondrial pathway to apoptosis is not required for neuronal loss.

LPS-induced neuronal loss was absent in cultures from Mfges knock-out mice, but could be reconstituted by adding recombinant MFG-E8. This is strong evidence that MFG-E8 is required for LPS-induced neuronal loss. Again, because in the absence of MFG-E8, LPS induces the same level of microglial proliferation and inflammation but no neuronal loss or death, it cannot be that MFG-E8 simply enables the removal of dead or dying neurons induced by LPS; otherwise, in the absence of MFG-E8, necrotic or apoptotic neurons would accumulate. It follows that MFG-E8 must enable the removal of viable neurons in inflammatory conditions. However, in the absence of LPS, addition of MFG-E8 has no effect on neuronal death or loss (Figs. $1 C, 3 D$ ), so MFG-E8 is necessary but not sufficient for neuronal removal. Addition of MFG-E8 to wild-type cultures in the presence of LPS induced no additional neuronal loss, indicating that the level of endogenously produced MFG-E8 was sufficient (rather than limiting) for neuronal loss. In contrast, the addition of D89E mutant MFG-E8 was not sufficient to reconstitute neuronal loss in $M f g e 8$ knock-out cultures (Fig. 3D), indicating that the ability to bind the vitronectin receptor is required for MFG-E8 to enable neuronal loss, in accordance with a requirement for their phagocytic uptake mediated by VR. Furthermore, adding back wild-type microglia to $M f g e 8$ knock-out cultures was sufficient to restore LPS-induced neuronal loss, indicating that microglia were a sufficient source of MFG-E8. While we could not detect $\beta$-galactosidase activity in microglia in vitro, we found that MFG-E8 produced by wild-type astrocytes (present in the glial cultures from which microglia were isolated) could opsonize microglia, indicating that wild-type microglia may have transferred astrocytic MFG-E8 to knock-out cultures thereby enabling phagocytosis.

In vivo, LPS injection into the striatum of mice and rats caused neuronal loss, which was reduced in $M f g e 8$ knock-out mice or by coinjection of cRGD. Again in both cases blocking the PS/MFGE8/VR pathway of phagocytosis had little or no effect on the LPS-induced inflammation but left live neurons, implying that phagocytosis is required for neuronal death. Consistent with microglial phagocytosis of neurons, we observed that LPS injection into the rat striatum induced the appearance of TUNEL-positive neuronal nuclei within microglia, which was inhibited by cRGD. This also suggests that neuronal nuclei can become TUNELpositive after, rather than before, microglial phagocytosis, as has previously been found (McIlroy et al., 2000).

The recognition of PS on apoptotic cells by macrophages is known to be anti-inflammatory and to contribute to the resolution of inflammation (Fadok et al., 1998; Jinushi et al., 2007). Blocking phagocytosis of PS-exposing neurons could therefore be expected to cause prolonged inflammation in the brain. However, we find here that blocking the MFG-E8 pathway, either by Mfges knock-out, MFG-E8 mutant, annexin V, PS antibodies or cRGD, had little or no effect on LPS-induced inflammation either in culture or in vivo. Thus, if there is an anti-inflammatory effect of phagocytosis in this system, it appears not to be mediated by the MFG-E8 pathway, and thus inhibiting this pathway does not exacerbate inflammation.

We have previously shown that inflammatory activated microglia induce reversible PS-exposure on viable neurons due to peroxynitrite released from these microglia (Neher et al., 2011). There are a variety of known receptors on phagocytes for PS exposed on target cells (Wu et al., 2006; Kinchen, 2010). We have found that blocking the PS/MFG-E8/VR pathway is sufficient to prevent neuronal loss, but this does not rule out other pathways being involved. A so-called PS receptor was identified by Li et al. (2003), but was later found not to be involved in phagocytosis of PS-exposed cells (Mitchell et al., 2006). However, a variety of other putative PS receptors or phagocytic pathways (such as Tim-4, Mer tyrosine kinase or $\mathrm{P}_{2} \mathrm{Y}_{6}$ ) might be involved in the inflammatory neuronal loss seen here. However, the neuroprotective effect resulting from selective inhibition of the MFG-E8 pathway indicates a nonredundant role for this pathway in primary phagocytosis.

Phagocytosis has in the past been regarded as being secondary to the target cell dying by apoptosis or necrosis. However, it is increasingly recognized that cell death can be caused by phagocytosis of viable PS-exposed cells (primary phagocytosis), for example during macrophage phagocytosis of aged erythrocytes (Föller et al., 2008) or activated neutrophils (Jitkaew et al., 2009). This may occur in part because the eat-me signal PS can be reversibly exposed on viable cells as a result of calcium or oxidant 
activation of the PS scramblase (responsible for PS exposure) and/or calcium, oxidant or ATP depletion-induced inhibition of the aminophospholipid translocase (which mediates internalization of exposed PS) (Tyurina et al., 2007; Jitkaew et al., 2009). We have previously shown that oxidants from activated microglia cause reversible PS exposure on cocultured neurons (Neher et al., 2011). In C. elegans, primary phagocytosis has been shown to contribute to programmed cell death during development (Hoeppner et al., 2001; Reddien et al., 2001) and elimination of cells subjected to subtoxic insults (Neukomm et al., 2011). Previous studies showed that inflammatory activation of microglia by amyloid- $\beta$ mediates neurodegeneration both in vitro and in vivo (Meda et al., 1995; Tan et al., 1999, 2002) and we recently found that microglia activated with nanomolar levels of amyloid- $\beta$ in vitro cause neuronal loss through primary phagocytosis (Neher et al., 2011; Neniskyte et al., 2011). Recent evidence also indicates that Frontotemporal Dementia can arise from inactivation of a gene product (progranulin) inhibiting phagocytosis of viable neurons (Kao et al., 2011). Thus primary phagocytosis is potentially involved in a variety of brain pathologies.

We conclude that under inflammatory conditions induced by LPS, microglia eat viable neurons via an MFG-E8-dependent pathway. Thus, blocking this pathway might be of therapeutic benefit in other inflammatory brain pathologies involving inflammation, such as stroke, trauma or neurodegenerative disease. More generally, our results support growing evidence that primary phagocytosis may be an important cause of cell death.

\section{References}

Andersson A, Covacu R, Sunnemark D, Danilov AI, Dal Bianco A, Khademi M, Wallström E, Lobell A, Brundin L, Lassmann H, Harris RA (2008) Pivotal advance: HMGB1 expression in active lesions of human and experimental multiple sclerosis. J Leukoc Biol 84:1248-1255.

Asano K, Miwa M, Miwa K, Hanayama R, Nagase H, Nagata S, Tanaka M (2004) Masking of phosphatidylserine inhibits apoptotic cell engulfment and induces autoantibody production in mice. J Exp Med 200:459-467.

Block ML, Zecca L, Hong JS (2007) Microglia-mediated neurotoxicity: uncovering the molecular mechanisms. Nat Rev Neurosci 8:57-69.

Chéret C, Gervais A, Lelli A, Colin C, Amar L, Ravassard P, Mallet J, Cumano A, Krause KH, Mallat M (2008) Neurotoxic activation of microglia is promoted by a nox1-dependent NADPH oxidase. J Neurosci 28:12039-12051.

Choi HB, Ryu JK, Kim SU, McLarnon JG (2007) Modulation of the purinergic P2X7 receptor attenuates lipopolysaccharide-mediated microglial activation and neuronal damage in inflamed brain. J Neurosci 27:4957-4968.

Deckwerth TL, Elliott JL, Knudson CM, Johnson EM Jr, Snider WD, Korsmeyer SJ (1996) BAX is required for neuronal death after trophic factor deprivation and during development. Neuron 17:401-411.

Dehmer T, Lindenau J, Haid S, Dichgans J, Schulz JB (2000) Deficiency of inducible nitric oxide synthase protects against MPTP toxicity in vivo. J Neurochem 74:2213-2216.

Elliott MR, Ravichandran KS (2010) Clearance of apoptotic cells: implications in health and disease. J Cell Biol 189:1059-1070.

Fadok VA, Bratton DL, Konowal A, Freed PW, Westcott JY, Henson PM (1998) Macrophages that have ingested apoptotic cells in vitro inhibit proinflammatory cytokine production through autocrine/paracrine mechanisms involving TGF-beta, PGE2, and PAF. J Clin Invest 101:890-898.

Föller M, Huber SM, Lang F (2008) Erythrocyte programmed cell death. IUBMB Life 60:661-668.

Fuller AD, Van Eldik LJ (2008) MFG-E8 regulates microglial phagocytosis of apoptotic neurons. J Neuroimmune Pharmacol 3:246-256.

Gao HM, Jiang J, Wilson B, Zhang W, Hong JS, Liu B (2002) Microglial activation-mediated delayed and progressive degeneration of rat nigral dopaminergic neurons: relevance to Parkinson's disease. J Neurochem 81:1285-1297.
Hanayama R, Tanaka M, Miwa K, Shinohara A, Iwamatsu A, Nagata S (2002) Identification of a factor that links apoptotic cells to phagocytes. Nature 417:182-187.

Hanisch UK, Kettenmann H (2007) Microglia: active sensor and versatile effector cells in the normal and pathologic brain. Nat Neurosci 10 : 1387-1394.

Haubner R, Gratias R, Diefenbach B, Goodman SL, Jonczyk A, Kessler H (1996) Structural and functional aspects of RGD-containing cyclic pentapeptides as highly potent and selective integrin alpha(v)beta(3) antagonists. J Am Chem Soc 118:7461-7472.

Hoeppner DJ, Hengartner MO, Schnabel R (2001) Engulfment genes cooperate with ced-3 to promote cell death in Caenorhabditis elegans. Nature 412:202-206.

Hoshino K, Takeuchi O, Kawai T, Sanjo H, Ogawa T, Takeda Y, Takeda K, Akira S (1999) Cutting edge: Toll-like receptor 4 (TLR4)-deficient mice are hyporesponsive to lipopolysaccharide: evidence for TLR4 as the Lps gene product. J Immunol 162:3749-3752.

Jinushi M, Nakazaki Y, Dougan M, Carrasco DR, Mihm M, Dranoff G (2007) MFG-E8-mediated uptake of apoptotic cells by APCs links the pro- and antiinflammatory activities of GM-CSF. J Clin Invest 117:1902-1913.

Jitkaew S, Witasp E, Zhang S, Kagan VE, Fadeel B (2009) Induction of caspase- and reactive oxygen species-independent phosphatidylserine externalization in primary human neutrophils: role in macrophage recognition and engulfment. J Leukoc Biol 85:427-437.

Kao AW, Eisenhut RJ, Martens LH, Nakamura A, Huang A, Bagley JA, Zhou P, de Luis A, Neukomm LJ, Cabello J, Farese RV Jr, Kenyon C (2011) neurodegenerative disease mutation that accelerates the clearance of apoptotic cells. Proc Natl Acad Sci U S A 108:4441-4446.

Kinchen JM (2010) A model to die for: signaling to apoptotic cell removal in worm, fly and mouse. Apoptosis 15:998-1006.

Kinsner A, Pilotto V, Deininger S, Brown GC, Coecke S, Hartung T, Bal-Price A (2005) Inflammatory neurodegeneration induced by lipoteichoic acid from Staphylococcus aureus is mediated by glia activation, nitrosative and oxidative stress, and caspase activation. J Neurochem 95:1132-1143.

Lamkanfi M (2011) Emerging inflammasome effector mechanisms. Nat Rev Immunol 11:213-220.

Lehnardt S, Schott E, Trimbuch T, Laubisch D, Krueger C, Wulczyn G, Nitsch $\mathrm{R}$, Weber JR (2008) A vicious cycle involving release of heat shock protein 60 from injured cells and activation of toll-like receptor 4 mediates neurodegeneration in the CNS. J Neurosci 28:2320-2331.

Li MO, Sarkisian MR, Mehal WZ, Rakic P, Flavell RA (2003) Phosphatidylserine receptor is required for clearance of apoptotic cells. Science 302:1560-1563

Lobsiger CS, Cleveland DW (2007) Glial cells as intrinsic components of non-cell-autonomous neurodegenerative disease. Nat Neurosci 10:1355-1360

McIlroy D, Tanaka M, Sakahira H, Fukuyama H, Suzuki M, Yamamura K, Ohsawa Y, Uchiyama Y, Nagata S (2000) An auxiliary mode of apoptotic DNA fragmentation provided by phagocytes. Genes Dev 14:549-558.

Meda L, Cassatella MA, Szendrei GI, Otvos L Jr, Baron P, Villalba M, Ferrari D, Rossi F (1995) Activation of microglial cells by beta-amyloid protein and interferon-gamma. Nature 374:647-650.

Mitchell JE, Cvetanovic M, Tibrewal N, Patel V, Colamonici OR, Li MO, Flavell RA, Levine JS, Birge RB, Ucker DS (2006) The presumptive phosphatidylserine receptor is dispensable for innate anti-inflammatory recognition and clearance of apoptotic cells. J Biol Chem 281:5718-5725.

Nadeau S, Rivest S (2002) Endotoxemia prevents the cerebral inflammatory wave induced by intraparenchymal lipopolysaccharide injection: role of glucocorticoids and CD14. J Immunol 169:3370-3381.

Neher JJ, Neniskyte U, Zhao JW, Bal-Price A, Tolkovsky AM, Brown GC (2011) Inhibition of microglial phagocytosis is sufficient to prevent inflammatory neuronal death. J Immunol 186:4973-4983.

Neniskyte U, Neher JJ, Brown GC (2011) Neuronal death induced by nanomolar amyloid beta is mediated by primary phagocytosis of neurons by microglia. J Biol Chem 286:39904-39913.

Neukomm LJ, Frei AP, Cabello J, Kinchen JM, Zaidel-Bar R, Ma Z, Haney LB, Hardin J, Ravichandran KS, Moreno S, Hengartner MO (2011) Loss of the RhoGAP SRGP-1 promotes the clearance of dead and injured cells in Caenorhabditis elegans. Nat Cell Biol 13:79-86.

Neumann H, Kotter MR, Franklin RJ (2009) Debris clearance by microglia: an essential link between degeneration and regeneration. Brain 132: $288-295$. 
Oshima K, Aoki N, Kato T, Kitajima K, Matsuda T (2002) Secretion of a peripheral membrane protein, MFG-E8, as a complex with membrane vesicles. Eur J Biochem 269:1209-1218.

Park JS, Svetkauskaite D, He Q, Kim JY, Strassheim D, Ishizaka A, Abraham E (2004) Involvement of toll-like receptors 2 and 4 in cellular activation by high mobility group box 1 protein. J Biol Chem 279:7370-7377.

Paxinos G, Franklin KBJ (2001) The mouse brain in stereotaxic coordinates, Ed 2. New York: Elsevier.

Paxinos G, Watson C (1982) The rat brain in stereotaxic coordinates. New York: Academic.

Ravichandran KS (2003) "Recruitment signals" from apoptotic cells: invitation to a quiet meal. Cell 113:817-820.

Reddien PW, Cameron S, Horvitz HR (2001) Phagocytosis promotes programmed cell death in C. elegans. Nature 412:198-202.

Savill J, Dransfield I, Gregory C, Haslett C (2002) A blast from the past: clearance of apoptotic cells regulates immune responses. Nat Rev Immunol 2:965-975.

Schmued LC, Stowers CC, Scallet AC, Xu L (2005) Fluoro-Jade C results in ultra high resolution and contrast labeling of degenerating neurons. Brain Res 1035:24-31.

Silvestre JS, Théry C, Hamard G, Boddaert J, Aguilar B, Delcayre A, Houbron C, Tamarat R, Blanc-Brude O, Heeneman S, Clergue M, Duriez M, Merval R, Lévy B, Tedgui A, Amigorena S, Mallat Z (2005) Lactadherin promotes VEGF-dependent neovascularization. Nat Med 11:499-506.

Sun YF, Yu LY, Saarma M, Timmusk T, Arumae U (2001) Neuron-specific
Bcl-2 homology 3 domain-only splice variant of Bak is anti-apoptotic in neurons, but pro-apoptotic in non-neuronal cells. J Biol Chem 276: $16240-16247$.

Tan J, Town T, Paris D, Mori T, Suo Z, Crawford F, Mattson MP, Flavell RA, Mullan M (1999) Microglial activation resulting from CD40-CD40L interaction after beta-amyloid stimulation. Science 286:2352-2355.

Tan J, Town T, Crawford F, Mori T, DelleDonne A, Crescentini R, Obregon D, Flavell RA, Mullan MJ (2002) Role of CD40 ligand in amyloidosis in transgenic Alzheimer's mice. Nat Neurosci 5:1288-1293.

Tyurina YY, Basova LV, Konduru NV, Tyurin VA, Potapovich AI, Cai P, Bayir H, Stoyanovsky D, Pitt BR, Shvedova AA, Fadeel B, Kagan VE (2007) Nitrosative stress inhibits the aminophospholipid translocase resulting in phosphatidylserine externalization and macrophage engulfment: implications for the resolution of inflammation. J Biol Chem 282:8498-8509.

Unal-Cevik I, Kilinç M, Gürsoy-Ozdemir Y, Gurer G, Dalkara T (2004) Loss of NeuN immunoreactivity after cerebral ischemia does not indicate neuronal cell loss: a cautionary note. Brain Res 1015:169-174.

Walter S, Letiembre M, Liu Y, Heine H, Penke B, Hao W, Bode B, Manietta N, Walter J, Schulz-Schäffer W, Fassbender K (2007) Role of the Toll-like receptor 4 in neuroinflammation in Alzheimer's disease. Cell Physiol Biochem 20:947-956.

Wu Y, Tibrewal N, Birge RB (2006) Phosphatidylserine recognition by phagocytes: a view to a kill. Trends Cell Biol 16:189-197. 